\title{
2 Paediatric cases of HIV related complications in Southern Africa
}

\section{Suzanne Kidd, Alastair Findlay. Senior House Officers NHS Greater Glasgow and Clyde}

\section{Zambia Case}

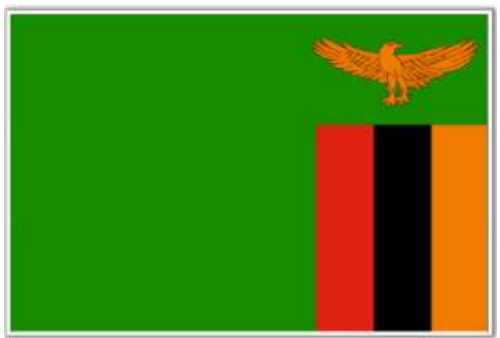

An 8 year old presented to a rural clinic for the first time with her mother with a series of problems including moderate malnutrition, chest wounds, diarrhoea, night blindness and cough.

- Her mother is HIV positive and is I of 4 wives to her husband

- Her CD4 count is 104 with $7 \%$ count

- She is Hepatitis B reactive and her USS abdomen shows fibrosis of liver parenchyma

- TB testing was negative but her chest $\mathbf{x}$-ray shows bilateral consolidation

- ART therapy commenced included lamivudine $75 \mathrm{mg} B D$, abacavir $150 \mathrm{mg}$ BD and efavirenz $300 \mathrm{mg}$.

- She was supposed to have her CD4 count checked in 2 weeks however due to living far from the rural hospital and during the wet season being blocked by a river, she failed to attend making it is uncertain if she will continue her ART medication.

\section{Malawi Case}

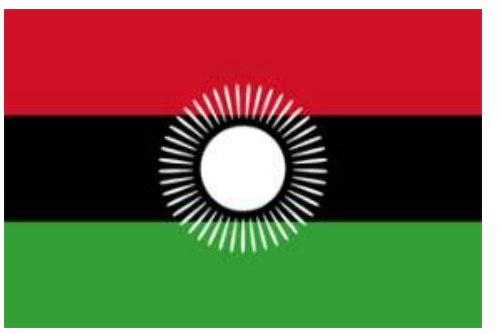

A I 4 year boy was transferred from a central hospital to district hospital with severe malnutrition, HIV treatment failure, deafness related to recurrent ear infections, chronic abdominal pain thought to be secondary to 3TC pancreatitis.

- On examination he had a GCS 9 E4M4VI and was pyrexial.

- He had voluntary guarding of his abdomen.

- Increase tone in all 4 limbs, power was unable to be assessed. He had nystagmus.

- He was commenced on ceftriaxone Ig OD on admission

- MRDT was negative.

- During his seizure activity on 3 occasions he was given paraldehyde $5 \mathrm{ml}$ as no other medication was available.

- The diagnosis of HIV was made in 2008 but the family were lost to follow up as they moved to Mozambique for a duration of time.

- His care became palliative as his viral load was 15000 and he had failed to respond to first line ART.
Percentage of children and adults living with HIV not accessing antiretroviral treatment, 2013
Southern Africa has some of highest rates of HIV with a prevalence of over $10 \%$ in the adult population. As we enter the second decade of the epidemic over I7.I million people in southern and eastern Africa live with the disease. In Zambia around 100,000 children under the age of 14 and in Malawi an estimated I 70, 000 children have HIV.

- In Zambia the child vs adult breakdown of ART coverage amongst HIV positive patients shows that only $26 \%$ of children have access to treatment compared to $84 \%$ of adults.

- In Malawi only $30 \%$ of HIV positive children receive treatment compared to $51 \%$ of adults.

- Only $30 \%$ of paediactric HIV cases in Malawi receive a diagnosis within the first 2 months of life.

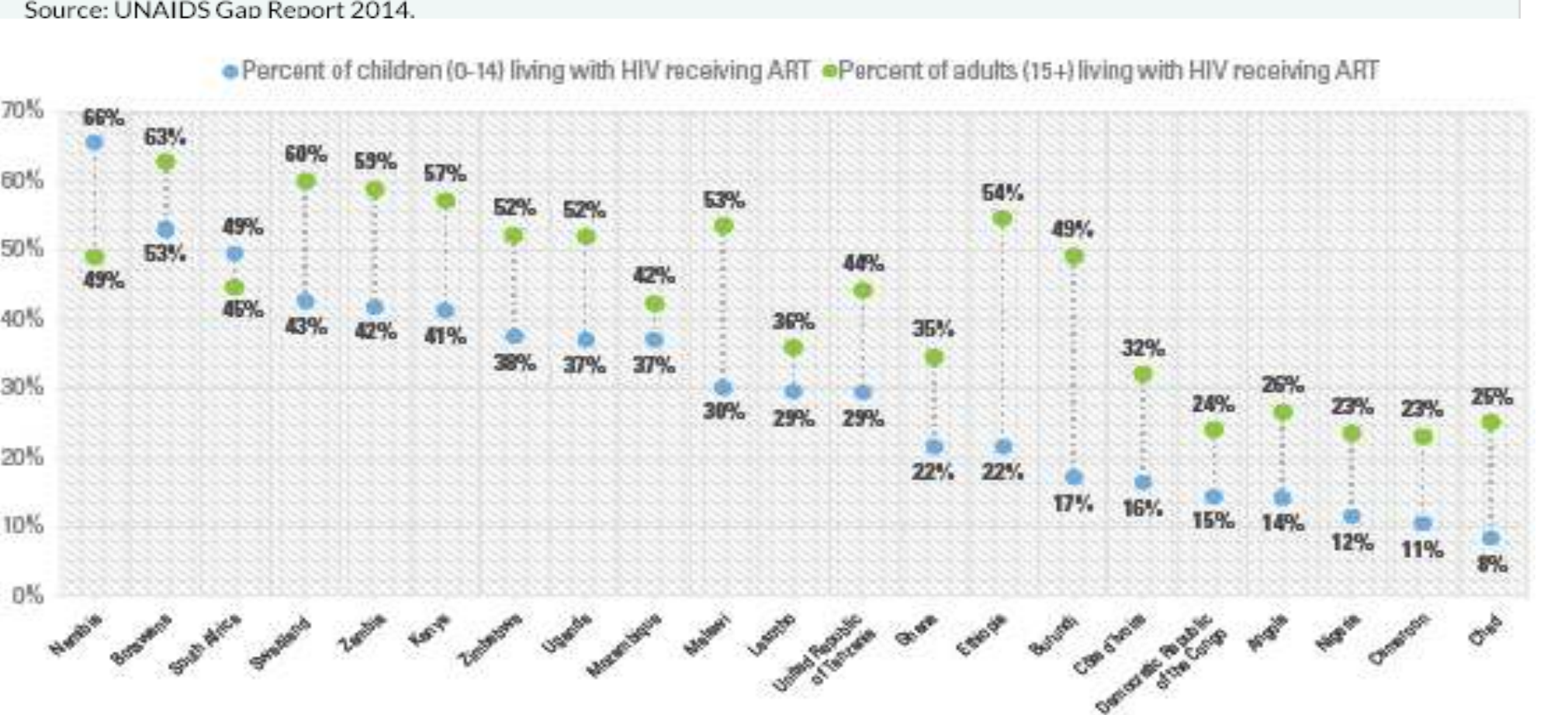

These cases explore the inequalities that children face with late diagnosis of HIV. The importance of providing ART to children who need it cannot be overestimated. Children have naturally less developed immune systems than adults and combined with HIV this can lead to severe and even life-threatening HIV/AIDS related complications as we have seen with $A B$.

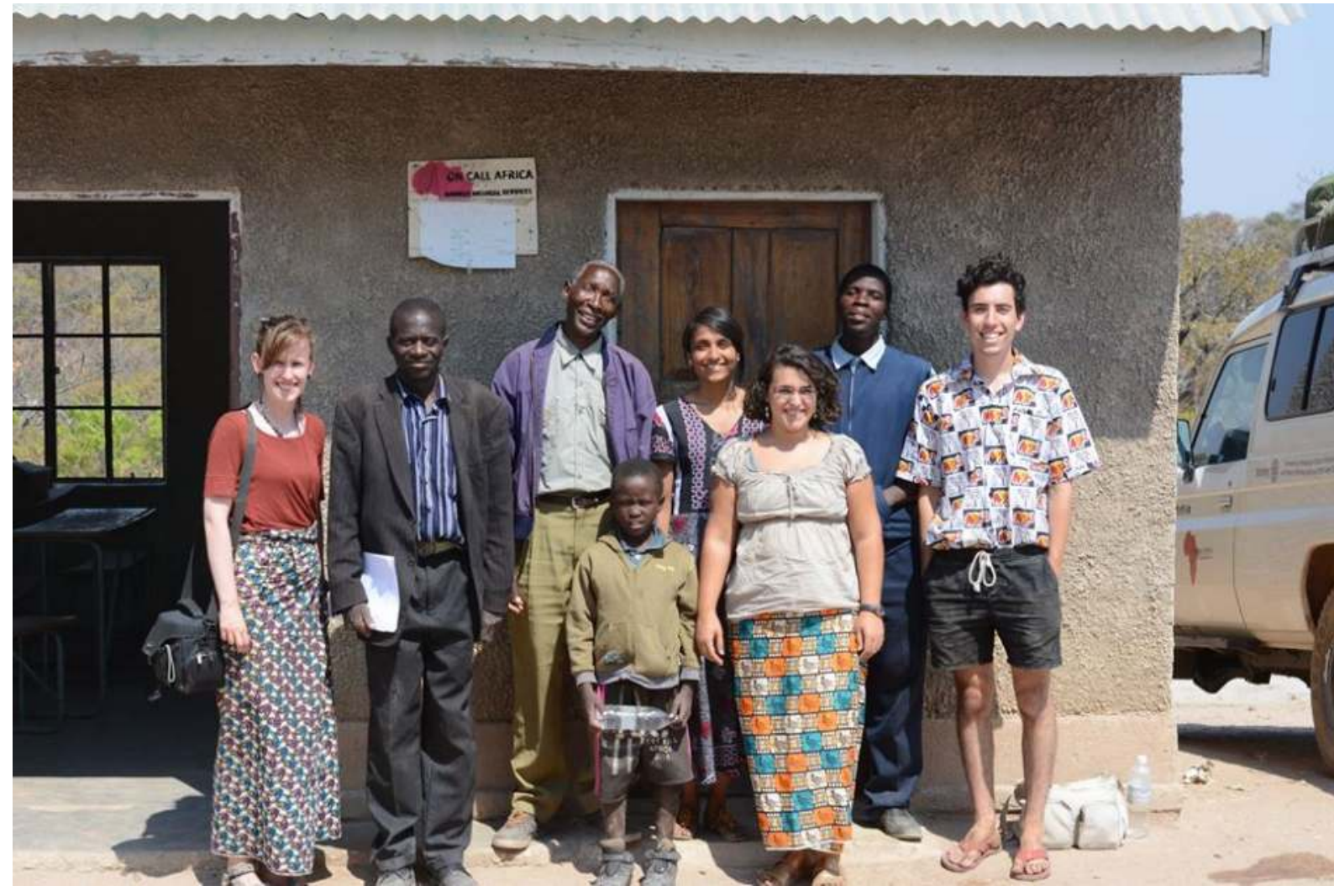

Copyright $(C 2013$

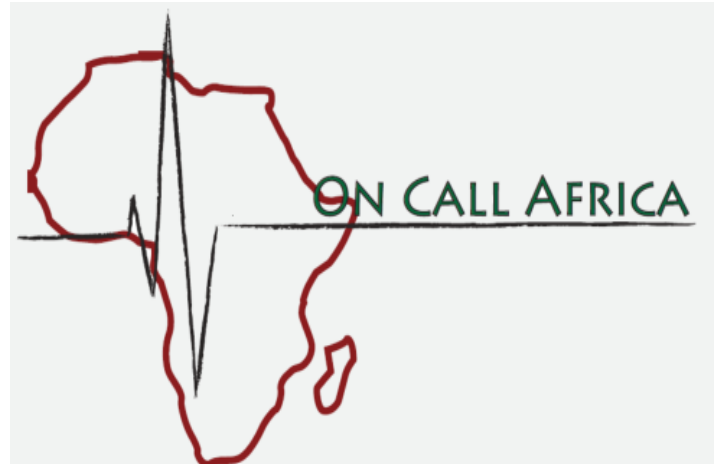

\section{References}

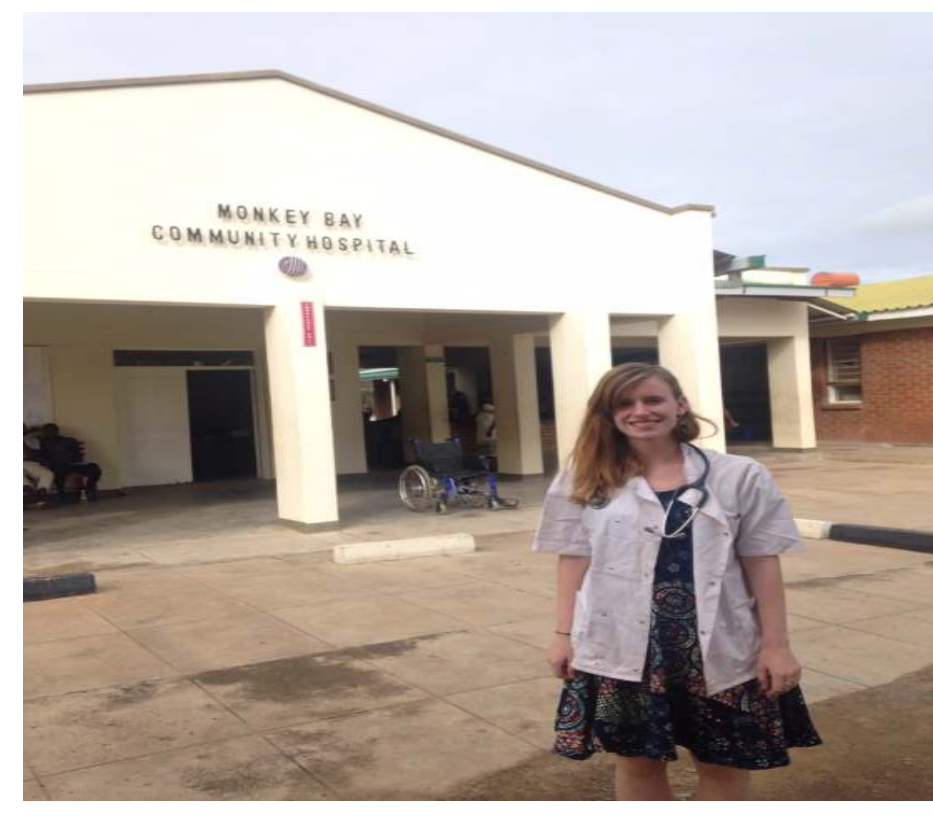

I. UNAIDS/UNICEF/WHO Global AIDS Response Progress Reporting and UNAIDS 2014 HIV and AIDS estimates, July 2015. http://data.unicef.org/hiv-aids/paediatric.html\#sthash.y4UMrQqk.dpuf

2. USAID: Rapid Assessment of Paediatric HIV treatment in Zambia. October 2012 